\title{
Un universo sonoro en Los ríos profundos ${ }^{1}$
}

\section{Chalena Vásquez}

\author{
Cada día invento el destino \\ cual gota que borada \\ la eterna piedra espacial \\ ¿Soy piedra? ¿Soy agua? \\ ¿O sonido infinito que persiste? \\ Chalena Vásquez
}

El compromiso de José María Arguedas con la problemática social del Perú, su persistente trabajo por la revalorización de las expresiones artísticas nativas, sus actividades como promotor de los artistas andinos, sus propias grabaciones de canciones en quechua, la inclusión de fragmentos de la letra de canciones y de referencias alusivas a la música y la danza en sus obras literarias, así como sus estudios en el campo de la etnología y su labor periodística, me llevaron a proponer

1 El presente artículo es un avance de un estudio mayor sobre la estética andina, partiendo del análisis de la música en la obra literaria de José María Arguedas. 
el estudio de la música en la obra del autor de Los ríos profundos, con la seguridad de encontrar otra dimensión o dimensiones de lo que significa este arte en la cultura andina.

Además de los artículos descriptivos de fiestas, danzas e instrumentos (aunque nunca se queda solamente en la descripción), Arguedas nos permite comprender la música andina a través de su obra literaria $^{2}$ y nos conduce a observarla como una partitura o la banda sonora de una película, que transcurre en toda la narración. Diríamos que la nueva poética ${ }^{3}$ trabajada por Arguedas contiene una matriz o elemento medular que es la música, o, mejor dicho, un mundo sonoro que en su plenitud abarca todo tiempo y todo espacio, no es de ninguna manera sólo una "música de fondo".

Esta matriz es el sonido -yllu- que captamos con todo nuestro organismo y no solamente con nuestros oídos. Al yllu, que es movimiento ${ }^{4}$ y que lo sentimos en todo nuestro ser psicofísico (físico-mental, material-espiritual), se une otro elemento medular: la luz -illa- que nos permite ver el color ${ }^{5}$.

En la poética de Arguedas encontramos el yllu, es decir sonido-movimiento, e illa, que es luz-color, enlazando la narración de acontecimientos próximos, inmediatos, con el hecho universal de la existencia. Una de las claves se encuentra en la comprensión de los mensajes o significados que cada motivo sonoro adquiere en la narración.

Lo curioso de este procedimiento literario es que el lector no andino no escuchará nada, simplemente imaginará paisajes y se conmoverá con las diferentes situaciones narradas, en tanto el lector andino, que tampoco escuchará nada en el momento de la lectura,

2 Una primera aproximación sobre el tema se encuentra en Montoya, Rodrigo (comp.). José María Arguedas, veinte años después: huellas y horizonte 1969-1989. Lima: Escuela de Antropología de la Universidad Nacional Mayor de San Marcos, 1991.

3 Rowe, William. Ensayos arguedianos. Lima: Universidad Nacional Mayor de San Marcos/Sur, 1996.

4 Sabemos que el sonido como fenómeno físico no existe por sí solo, el sonido siempre es movimiento de alguna materia que contiene a su vez energía.

5 Illa viene a ser también como la réplica de un ser en otro, generalmente en miniatura. 
comprenderá de otra forma dicho mundo sonoro, pues lo guarda en su propia memoria por experiencia vivida.

La poética arguediana incorpora al texto las referencias de luz y sonido de una manera imprescindible, no accidental -ni incidentallogrando, pese a la mediación de la escritura/lectura, que dichos elementos sean asumidos plenamente por el lector, aunque éste no hubiera sido partícipe de tales ambientes sonoros. Cada lector tiene a su vez, en su propia memoria auditiva, su propio mundo sonoro que le sirve como referencia para la interpretación.

Para América Latina, Arguedas inicia una nueva perspectiva en la musicología, pues para comprender la cultura musical andina hay que comprender el mundo sonoro significativo, que desborda el concepto de música al estilo occidental; mundo que está formado por los múltiples e infinitos mensajes que a través del sonido/movimiento están emitiendo todos los seres que conviven en el universo: piedras, ríos, montañas, aire, astros, insectos, aves, humanos. Es decir, una nueva musicología, producto de una visión integral, holística, que permite aproximarnos a las normas socioculturales de la estética andina en dimensiones insospechadas.

Desde esta perspectiva, otra será la significación de la sonoridad lograda en los instrumentos musicales, la construcción de géneros musicales, el balance sonoro de los conjuntos instrumentales, la técnica de la voz, pero, por sobre todo, otra será la significación de la música en el sentir humano y en la construcción de la identidad propia, individual y colectiva, así como otro será el significado del silencio.

\section{Los ríos profundos}

A través de los once capítulos que forman Los ríos profundos es posible observar los motivos sonoros a los que se alude implícita o explícitamente, y cómo van adquiriendo diversos significados de acuerdo con el momento descrito, a la intensidad y tipo de sentimiento o emoción que viven los personajes en la novela ${ }^{6}$.

6 Las citas textuales, que aparecen casi en el mismo orden que en la novela, han sido extraídas de Arguedas, José María. Los ríos profundos. Obras completas. Tomo III. Editorial Horizonte, 1983. 


\section{¿Las piedras hablan?}

Arguedas inicia la incorporación del sonido en Los ríos profundos con el asunto más difícil, quizás, de toda la novela: escribir sobre el mensaje de las piedras en diversas construcciones de la ciudad del Cusco.

Eran más grandes y extrañas de cuanto había imaginado las piedras del muro incaico; bullían bajo el segundo piso encalado que por el lado de la calle angosta era ciego. Me acordé, entonces, de las canciones quechuas que repiten una frase patética constante: "yawar mayu", río de sangre; "yawar unu", agua sangrienta; "puk' tik yawar k'ocha", lago de sangre que hierve; yawar wek'e" lágrimas de sangre 7 . ¿Acaso no podría decirse "yawar rumi", piedra de sangre o "puk' tik yawar rumi, piedra de sangre hirviente? Era estático el muro, pero hervía por todas sus líneas y la superficie era cambiante, como la de los ríos en el verano, que tienen una cima así hacia el centro del caudal, que es la zona temible, la más poderosa. Los indios llaman "yawar mayu" a esos ríos turbios, porque muestran con el sol un brillo en movimiento, semejante al de la sangre. También llaman "yawar mayu" al tiempo violento de las danzas guerreras, al momento en que los bailarines luchan. Puk' tik' yawar rumi! Exclamé frente al muro, en voz alta. (p. 14).

"Piedra de sangre que hierve" repitió varias veces el protagonista, mientras la calle seguía en silencio. Quizás el nombre en quechua de esta novela se hubiera derivado de ese concepto del yawar $m a y u^{8}$, el río de sangre hirviente. Si son varios los ríos profundos, uno

7 Con frecuencia se encuentra en los versos de canciones la expresión 'lágrimas de sangre'. Llorar lágrimas de sangre es manifestación de una gran aflicción. Sin embargo, el agua y la sangre son elementos similares, líquidos de distinto color. Se entiende que los ríos son la sangre de la tierra, y la sangre de los humanos es agua roja.

8 El yawar mayu es parte fundamental en algunas danzas andinas, así como en la representación del maqt'a, mezcla de pongo y bufón, que como personaje independiente participa en algunas comparsas cusqueñas.

La canción del yawar mayu, en el Cusco, dice: "Hermanito, no vayas a llorar, aunque tengas que atravesar un río de sangre, aunque caiga la granizada". Durante la interpretación de este canto los danzantes se azotan las piernas hasta sangrar. Se dice que la sangre que cae ayuda a fertilizar la tierra. Este canto da fuerza a los danzantes.

El yawar mayu, se dice, es el río que toda persona tiene que atravesar luego que muere, para pasar a otra dimensión de la existencia. La muerte es el paso a otra existencia (Vásquez R., Chalena. Danzas de Paucartambo. Inédito, 1985). 
sin duda es éste, el que se encuentra hasta en las piedras hirvientes de sangre, aquéllas de los muros incaicos del Cusco, en las que Ernesto percibe mensajes especiales.

Papá, le dije, cada piedra habla. Esperemos un instante (...)

Los incas están muertos (dice el padre).

Pero no este muro. ¿Por qué no lo devora, si el dueño es avaro? Este muro puede caminar; podría elevarse a los cielos o avanzar hacia el fin del mundo y volver. ¿No temen quienes viven adentro? (p. 15).

Quienes viven adentro sin duda no son indios, y ¿qué deberían temer?, ¿acaso las piedras podrían levantarse como testigos de una historia injusta y violenta?

Mi padre me llevó al atrio. Subimos las gradas. (...) Nuestras pisadas resonaban sobre la piedra. (...) En el silencio, las torres y el atrio repetían la menor resonancia, igual que las montañas de roca que orillan los lagos helados. La roca devuelve profundamente el grito de los patos o la voz humana. Ese eco es difuso y parece que naciera del propio pecho del viajero, atento, oprimido por el silencio.

Los motivos sonoros, la voz del río y el silencio, están expuestos en los primeros párrafos de la novela, la voz del río se ubicará en diversos sujetos, y se intensificará de diversas formas en los capítulos siguientes; el silencio aparecerá también y se sentirá como opresión.

El pongo esperaba en la puerta. Se quitó la montera, y así descubierto, nos siguió hasta el tercer patio. Venía sin hacer ruido, con los cabellos revueltos, levantados. Le hablé en quechua. Me miró extrañado (p. 16).

- ¿No sabe hablar? -le pregunté a mi padre.

- No se atreve -me dijo (p. 19).

El silencio, que es opresión y es miedo, es también misterio o enigma.

Al ver la condición del pongo, quien al retirarse se inclina "como un gusano que pidiera ser aplastado" el protagonista nos dice:

No pude contener el llanto. Lloré como al borde de un gran lago desconocido (pp. 19-20).

El pongo tiene el silencio de un lago desconocido, no tiene la voz de los ríos profundos. Las piedras parece que tuvieran más vida. 
¿Cantan de noche las piedras?

Es posible.

Como las más grandes de los ríos o de los precipicios. Los incas tendrían la historia de todas las piedras con "encanto" y las harían llevar para construir la fortaleza. ¿Y éstas con que levantaron la catedral?

Los españoles las cincelaron. Mira el filo de la esquina de la torre.

Aún en la penumbra se veía el filo; la cal que unía cada piedra labrada lo hacía resaltar.

Golpeándolas con cinceles les quitaron el "encanto"... (p. 17).

Las piedras también cambian de voz o enmudecen por circunstancias distintas, como distintas son las piedras de la calle Loreto, de la catedral, las del palacio de Huayna Cápac.

El Amaru Cancha, palacio de Huayna Cápac era una ruina, desmoronándose en la cima (...).

La calle era lúcida, no rígida. Si hubiera sido tan angosta, las piedras rectas se habrían, quizá, desdibujado. Así estaba cerca; no bullían, no hablaban, no tenían la energía de las que jugaban en el muro del palacio de Inca Roca; era el muro quien imponía silencio; y si alguien hubiera cantado con hermosa voz, allí las piedras habrían repetido con tono perfecto, idéntico, la música (p. 18).

A medida que van apareciendo los personajes humanos de la novela -Ernesto, su padre, el viejo, el pongo- la referencia permanente al ambiente y los espacios que recorren, hace que también sea presentado el mundo sonoro de personajes no humanos y sus múltiples mensajes.

El poder del sonido, es decir su capacidad transformadora, es planteado explícitamente en la voz de la campana, la María Angola y sus illas lejanas, aquellas campanas que al borde de los lagos se encuentran transformando al amaru -serpiente mítica- en toro.

Yo sabía que la voz de la campana llegaba a cinco leguas de distancia. Creí que estallaría en la plaza. Pero surgía lentamente, a intervalos suficientes; y el canto se acrecentaba, atravesaba los elementos; y todo se convertía en esa música cusqueña, que abría las puertas de la memoria.

En los grandes lagos, especialmente en los que tienen islas y bosques de totora hay campanas que tocan a la medianoche. A su canto triste salen del agua toros de fuego, o de oro, arrastrando cadenas; suben a las cumbres y mugen en la helada; porque en el Perú los lagos están 
en la altura. Pensé que esas campanas debían de ser illas, reflejos de la María Angola, que convertiría a los amarus en toros. Desde el centro del mundo, la voz de la campana, hundiéndose en los lagos, habría transformado a las antiguas criaturas (p. 19).

La dimensión utópica del texto se transforma luego cuando, refiriéndose a la misma campana, Ernesto describe el pequeño espacio que la rodea:

Comenzó en ese instante, el primer golpe de la María Angola. Nuestra habitación, cubierta de hollín hasta el techo, empezó a vibrar con las ondas lentas del canto. La vibración era triste, la mancha del hollín se mecía como un trapo negro. Nos arrodillamos para rezar. Las ondas finales se percibían todavía en el aire, apagándose, cuando llegó el segundo golpe aún más triste (pp. 20-21).

El capítulo termina saliendo del Cusco y anunciando el encuentro con el Apurímac, dios que habla, río profundo cuyo sonido será una y otra vez evocado en los capítulos siguientes y en otras obras de José María Arguedas.

Las montañas, el aire, el agua del río, los cañaverales... el paisaje sonoro externo inunda y agita el alma humana, despertando la memoria y contagiando el interior, como si de pronto, de repente, el paisaje transformara lo más íntimo, llenándolo con su luz y su brillo, con la sonoridad del río y la transparencia del aire.

En la tarde llegamos a la cima de las cordilleras que cercan al Apurímac. "Dios que habla" significa el nombre de este río.

El forastero lo descubre casi de repente, teniendo ante sus ojos una cadena sin fin de montañas negras y nevados, que se alternan. El sonido del Apurímac alcanza las cumbres, difusamente, desde el abismo, como un rumor del espacio.

El río corre entre bosques negruzcos y mantos de cañaverales que sólo crecen en las tierras quemantes. Los cañaverales reptan las escarpadas laderas o aparecen suspendidos en los precipicios. El aire transparente de la altura va tornándose denso hacia el fondo del valle.

La voz del río y la hondura del abismo polvoriento, el juego de la nieve lejana y las rocas que brillan como espejos, despiertan en su memoria los primitivos recuerdos, los más antiguos sueños (p. 26).

El sueño, que puede ser recuerdo y premonición, palpita en un instante mágico: 
A medida que baja al fondo del valle el recién llegado se siente transparente, como un cristal en que el mundo vibrara ${ }^{9}$. Insectos zumbadores aparecen en la región cálida; nubes de mosquitos venenosos se clavan en el rostro. El viajero oriundo de las tierras frías se acerca al río, aturdido, febril, con las venas hinchadas. La voz del río aumenta; no ensordece, exalta. A los niños los cautiva, les infunde presentimientos de mundos desconocidos. Los penachos de los bosques de carrizo se agitan junto al río. La corriente marcha como a paso de caballos de grandes caballos cerriles.

¡Apurímac mayu! ¡Apurímac mayu! Repiten los niños de habla quechua con ternura y algo de espanto (p. 26).

Y no será esa la única mención a los caballos como símbolo de plenitud, de libertad para transcurrir por el camino propio, por su propio cauce.

\section{Cantos}

Leer el segundo capítulo de Los viajes es ingresar a diversos paisajes sonoros, en los que cada ser tiene voz propia:

El arrayán, los lambras, el sauce, el eucalipto, el capulí, la tara, son árboles de madera limpia, cuyas ramas y hojas se recortan libremente. El hombre los contempla desde lejos; y quien busca sombra se acerca a ellos y reposa bajo un árbol que canta solo, con una voz profunda, en que los cielos, el agua y la tierra se confunden (p. 27).

Y donde los seres humanos saben percibir, esperar, ver y escuchar, hasta incorporar la fuerza de la naturaleza -el río- aspirando su luz. Por eso también se comprende que incorporar el canto de otros es estar encantado.

Los hombres nadan para alcanzar las grandes piedras, cortando el río llegan a ellas y duermen allí. Porque de ningún otro sitio se oye mejor el sonido del agua. En los ríos anchos y grandes no todos llegan hasta las piedras. Sólo los nadadores, los audaces, los héroes; lo demás, los humildes y los niños se quedan; mirando desde la orilla, cómo los fuertes nadan en la corriente, donde el río es hondo, cómo llegan hasta las piedras solitarias, cómo las escalan, con cuánto trabajo, y luego se

9 Subrayo frases o imágenes que sintetizan luz y sonido. La luz no es objeto de análisis en este artículo. 
yerguen para contemplar la quebrada, para aspirar la luz del río, el poder con que marcha y se interna en las regiones desconocidas (p. 27).

Párrafo especial dedica José María Arguedas para describir cómo una persona que no baila, no canta ni toca ningún instrumento - cosa que es rara en la cultura andina- comparte el hecho musical participando como receptor que guarda en su memoria cada nota, cada ritmo, cada verso o timbre instrumental, viviendo a plenitud el momento mágico que acompañe o transforme su ser íntimo.

A mi padre le gustaba oír huaynos; no sabía cantar, bailaba mal, pero recordaba a qué pueblo, a qué comunidad, a qué valle pertenecía tal o cual canto. A los pocos días de haber llegado a un pueblo averiguaba quién era el mejor arpista, el mejor tocador de charango, de violín y de guitarra. Los llamaba, y pasaban en la casa toda una noche. En esos pueblos sólo los indios tocan arpa y violín. (...)

Las habitaciones eran grandes, los músicos tocaban en una esquina. Los arpistas indios tocan con los ojos cerrados. La voz del arpa parecía brotar de la oscuridad que hay dentro de la caja; y el charango formaba un torbellino que grababa en la memoria la letra y la música de los cantos (pp. 27-28).

Escuchar, mejor dicho saber escuchar y no solamente oír, abarca un conocimiento mayor que la simple percepción sonora. El sonido que se oye es mensaje; no es un sonido que solamente causa placer o desagrado en el escucha, sino que se recibe como algo que transmiten los seres que lo emiten. Arguedas sitúa al lector en un asunto central en la cultura andina, cual es el entender que todos los seres existentes en el universo se relacionan como sujetos activos, donde el ser humano es uno más en este mundo natural y que a los otros seres, como criaturas del universo se les conoce -y se aprende de ellas- en tanto se les sabe escuchar, ver y sentir.

Los sonidos naturales de las aves, el viento, el rumor del río, así como el brillo u opacidad de los astros, las estrellas, el color de las hojas, de la madera, de la tierra, es fuente de información permanente sobre las necesidades de estos otros seres, de su funcionamiento, de su transcurrir vital; en este transcurrir se entiende lo natural y lo social-humano como partes inseparables del cosmos en funcionamiento.

En los pueblos, a cierta hora, las aves se dirigen visiblemente a lugares ya conocidos. A los pedregales, a las huertas, a los arbustos que crecen 
en la orilla de las aguadas. Y según el tiempo, su vuelo es distinto. La gente del lugar no observa estos detalles ${ }^{10}$, pero los viajeros, la gente que ha de irse, no los olvida. Las tuyas prefieren los árboles altos, los jilgueros duermen o descansan en los arbustos amarillos; el chihuaco canta en los árboles de hojas oscuras: el sauco, el eucalipto, el lambras; no va a los sauces. Las tórtolas vuelan a las paredes viejas y horadadas; las torcazas buscan las quebradas, los pequeños bosques de apariencia lejana; prefieren que se les oiga a cierta distancia. El gorrión es el único que está en todos los pueblos y en todas partes. La vida-pisk'o salta sobre las grandes matas de espino, abre las alas negras, las sacude, y luego grita. Los loros grandes son viajeros. Los loros pequeños prefieren los cactos, los árboles de espino. Cuando empieza a oscurecer se reparten todas esas aves en el cielo; según los pueblos toman diferentes direcciones, y sus viajes los recuerda quien las ha visto, sus trayectos no se confunden en la memoria (p. 28).

La memoria, imprescindible para el funcionamiento humano, es conocimiento intelectual a la vez que subjetividad, es pensamiento y emoción; es un caudal o una fuente desde la cual se asumen conductas y se generan y regeneran también pensamientos, emociones y sentimientos, de acuerdo con la nueva circunstancia vivida; los recuerdos pueden revitalizar a las personas.

Cuando salía en la noche, los sapos croaban a intervalos; su coro frío me acompañaba varias cuadras. Llegaba a la esquina, y junto a la tienda de aquella joven que parecía ser la única que no miraba con ojos severos a los extraños, cantaba huaynos de Querobamba, de Lambrama, de Sañayca, de Toraya, de Andahuaylas... de los pueblos más lejanos; cantos de las quebradas profundas. Me desahogaba; vertía el desprecio amargo y el odio con que en ese pueblo nos miraban, el fuego de mis viajes por las grandes cordilleras, la imagen de tantos ríos, de los puentes que cuelgan sobre el agua que corre desesperada, la luz resplandeciente y la sombra de las nubes más altas y temibles. Luego regresaba a mi casa, despacio, pensando con lucidez en el tiempo en que alcanzaría la edad y la decisión necesarias para acercarme a una mujer hermosa; tanto más bella si vivía en pueblos hostiles (p. 30).

10 Pienso que no es que no observen los detalles, sino que son obvios, "ya se sabe todo aquello", es tan obvio y natural que no se habla necesariamente de estos hechos; sin embargo, en las canciones, en las danzas, en las artes plásticas, como textiles, retablos, etc., toda esta información y conocimiento, se expresa artísticamente. 
El canto de los humanos o de otros seres tiene lugar de privilegio para la comunicación en el mundo andino; tanto así que para una comunicación plena no basta la voz hablada, ésta puede transmitir un discurso intelectual, con algo de emoción e intención, de acuerdo con la intensidad, el timbre, el dejo o la forma cotidiana del habla cantada... sin embargo, es con la canción que se funden intelecto y emoción, lo objetivo y lo subjetivo; es la canción, la forma que permite la comunicación más allá o más acá de lo pensado, el canto permite la comunicación con otros seres de la naturaleza, como con las aves, por ejemplo, cuando se necesita espantarlas del trigal, los niños

Ruegan a los pájaros en sus canciones, les avisan “Está envenenado el trigo! ¡Idos, idos! Volad, volad. Es del señor cura. ¡Salid! ¡Buscad otros campos!"” (p. 29).

O cuando se canta en Huancapi:

Oye cernícalo,

oye gavilán

voy a quitarte a tu paloma

a tu amada voy a quitarte.

He de arrebatártela

me la he de llevar,

me la he de llevar

oh cernícalo

oh gavilán

El desafío es igual, al cernícalo, al gavilán o al cóndor. Junto a las grandes montañas, cerca de los precipicios donde anidan las aves de presa, cantan los indios en este mes seco y helado. Es una canción de las regiones frías, de las quebradas altas de los pueblos de estepa, en el sur (pp. 31-32).

Cada canto o canción tiene su sentido, su intención, su lugar y su momento, por eso Arguedas incluye en la novela referencias de carácter etnográfico. Porque la descripción, plena de poesía y lirismo, que pudiera pensarse como producto de una fértil e inspirada imaginación, pertenece a un mundo real, no imaginado, sino plenamente sentido.

Ya debía amanecer. Habíamos llegado a la región de los lambras, de los molles y de los árboles de tara. Bruscamente, del abra en que nace el torrente, salió una luz que nos iluminó por la espalda. Era una estrella más luminosa y helada que la luna. Cuando cayó la luz en la 
quebrada, las hojas de los lambras brillaron como la nieve; los árboles y las yerbas parecían témpanos rígidos; el aire mismo adquirió una especie de sólida transparencia. Mi corazón latía como dentro de una cavidad luminosa ${ }^{11}$ (p. 32).

\section{La despedida}

En el tercer y cuarto capítulos, el protagonista se despide de su padre para quedarse a vivir interno en un colegio. Otro mundo sonoro será explorado y el protagonista recurrirá permanentemente a su caudal de experiencias sonoras, tomando de su memoria la fuerza para resistir, en el mundo hostil en el que se encuentra. El niño se siente solo e interpreta la soledad del padre como un estado de gran crueldad y silencio interior.

Después de varios años de haber viajado juntos, yo debía quedarme; y él se iría solo (...). Y entraría en otro valle o pampa, ya solo; sus ojos no verían del mismo modo el cielo ni la lejanía; trotaría entre las piedras y los arbustos sin poder hablar; con gran crueldad y silencio en su interior (p. 36). (...)

Yo exploraría palmo a palmo el gran valle y el pueblo; recibiría la corriente poderosa y triste que golpea a los niños, cuando deben enfrentar solos a un mundo cargado de monstruos y de fuego, y de grandes ríos que cantan con la música más hermosa al chocar contra las piedras y las islas (p. 39).

\section{Jarahui}

Uno de los pocos géneros musicales que no se baila en los Andes es el harawi o jarahui. Ya en el internado, Ernesto recuerda un harawi de despedida que le dedicaron unas mujeres cuando salía de un caserío con su padre. El harawi es canto y es llanto, dolor y esperanza, oración, plegaria, palabra mágica, intensa y amorosa.

Ay, warmallay warma

yayaykunkim, yuyaykunkim

Jhatun yurak'ork'o

kutiykachimunki;

11 La cursiva es nuestra. 
abrapi puquio, pampapi puquio

yank'atak'yakuyananman

Alkunchallay kutiykamunchu

raprachaykipi apaykamunki

Riti ork'o, jhatun riti ork'o

yank'a tak' ñannimpi ritiwak;

yank'atak wayra

ñannimpi k'ochpaykunkiman.

Amas pára amas pára

aypankichu

Amas k'ak'a, amas k'ak'a

ñannimpi tuñinkichu

¡Ay warmallay warma

kutiykamunki

kutiykamunkipuni!

¡No te olvides, mi pequeño

no te olvides!

Cerro blanco,

hazlo volver;

agua de la montaña

manantial de la pampa

que nunca muera de sed.

Halcón, cárgalo en tus alas

y hazlo volver

Inmensa nieve, padre de la nieve no lo hieras en el camino.

Mal viento,

no lo toques

Lluvia de tormenta,

No lo alcances

¡No, precipicio, atroz precipicio

no lo sorprendas!

¡Hijo mío,

has de volver

has de volver! (pp. 42-43) 


\section{Puentes: el río y la música}

La traducción literal de Pachachaca es puente sobre el mundo. Sin embargo, en la novela de José María Arguedas, el Pachachaca es el puente entre dos mundos del protagonista: el del internado y el del cosmos andino que se encontraba fuera del colegio.

A veces, podía llegar al río, tras varias horas de andar. Llegaba a él cuando más abrumado y doliente me sentía. Lo contemplaba, de pie sobre el releje del gran puente, apoyándome en una de las cruces de piedra que hay clavadas en lo alto de la columna central. (...)

$\mathrm{Al}$ atardecer, el agua que salta de las columnas, forma arco iris fugaces que giran con el viento.

Yo no sabía si amaba más al puente o al río. Pero ambos despejaban mi alma, la inundaban de fortaleza y de heroicos sueños. Borraban de mi mente todas las imágenes plañideras, las dudas y los malos recuerdos. Y así renovado, vuelto a mi ser, regresaba al pueblo; subía la temible cuesta con pasos firmes. Iba conversando mentalmente con mis viejos amigos lejanos: don Maywa, don Demetrio Pumaylli, don Pedro Kokchi... que me criaron, que hicieron mi corazón semejante al suyo.

Durante muchos días después me sentía solo, firmemente aislado (p. 60).

Desde el renovado mundo interior, sintiéndose distinto a ese otro mundo hostil, podía mantener la serenidad y cultivar sentimientos diferentes frente a los sucesos violentos del internado, invocando al río.

Y podía ir al patio oscuro, dar vueltas en su suelo polvoriento, aproximarse a los tabiques de madera y volver más altivo y sereno a la luz del patio principal. La propia demente me causaba una gran lástima. Me apenaba recordarla sacudida, disputada con implacable brutalidad; su cabeza golpeada contra las divisiones de madera, contra la base de los excusados; y su huida por el callejón, en que corría como un oso perseguido. Y los pobres jóvenes que la acosaban y que después se profanaban, hasta sentir el ansia de flagelarse y llorar bajo el peso del arrepentimiento.

¡Sí!, había que ser como ese río imperturbable y cristalino, como sus aguas vencedoras. ¡Como tú, río Pachachaca! ¡Hermoso caballo de crin brillante, indetenible y permanente, que marcha por el más profundo camino terrestre! (p. 47).

Sábados y domingos, en el pueblo, acudía a las chicherías para encontrar la música que su soledad necesitaba. 
Yo iba a las chicherías a oír cantar y a buscar a los indios de hacienda. Deseaba hablar con ellos y no perdía la esperanza.

(...) iba a las chicherías, por oír la música, y a recordar. Acompañando en voz baja la melodía de las canciones, me acordaba de los campos y las piedras, de las plazas y los templos, de los pequeños ríos donde fui feliz. Y podía permanecer muchas horas junto al arpista o en la puerta de calle de las chicherías, escuchando. Porque el valle cálido, el aire ardiente, y las ruinas cubiertas de alta yerba de los otros barrios, me eran hostiles.

¡Ay, siwar k'enti!

amaña wayta tok'okachaychu,

siwar k'enti.

Ama jhina kaychu

mayupataman urayamuspa,

k'ori raphra,

kay puka mayupi wak'ask'ayta

k'awaykamuway.

K'awaykamuway

siwar k'enti, k'ori raphra,

llakisk"yta

purunwayta kirisk'aykita

mayupata wayta

sak'esk'aykita.

¡Ay picaflor!, ya no horades tanto la flor,

alas de esmeralda.

No seas cruel

baja a la orilla del río,

alas de esmeralda,

y mírame llorando junto al agua roja,

mírame llorando.

Baja y mírame,

picaflor dorado,

toda mi tristeza,

flor del campo herida,

flor de los ríos

que abandonaste (p. 46).

Las sutilezas técnicas de la interpretación musical, los timbres, adornos, intensidades, ritmo, melodía, velocidad de las canciones, 
plasman la diversidad natural de los paisajes andinos y sus infinitas posibilidades.

Las canciones pertenecen a cada lugar geográfico donde nacieron y son propiedad de la gente de cada lugar. Tanto el sentido de pertenencia territorial como el de propiedad colectiva del arte, permiten cultivar formas de identidad.

Las características concretas del lenguaje musical varían, perfilándose estilos musicales distintos, factibles de ser distinguidos a través de la observación atenta, como se observan los ríos.

Las chicherías recibían gente desde el mediodía, pero sólo en la tarde y en la noche de los sábados y domingos iban los músicos. Cualquier parroquiano podía pedir que tocaran el huayno que prefería. Era difícil que el arpista no lo supiera. A las chicherías van más forasteros que a un tambo. Pero ocurría, a veces, que el parroquiano venía de tierras muy lejanas y distintas; de Huaraz, de Cajamarca, de Huancavelica o de las provincias del Collao, y pedía que tocaran un huayno completamente desconocido. Entonces los ojos del arpista brillaban de alegría; llamaba al forastero y le pedía que cantara en voz baja. Una sola vez era suficiente. El violinista lo aprendía y tocaba; el arpa acompañaba. Casi siempre el forastero rectificaba varias veces: "No; no es así. ¡No es así su genio!". Y cantaba en voz alta, tratando de imponer la verdadera melodía. Era imposible. El tema era idéntico, pero los músicos convertían el canto en huayno apurimeño, de ritmo vivo y tierno. “iManam!”, gritaban los hombres que venían de las regiones frías; los del Collao enfurecían, y si estaban borrachos, hacían callar a los músicos amenazándolos con los grandes vasos de chicha. "igual es señor!" protestaba el arpista. "No, alk'o - perro-", vociferaba el collavino. Ambos tenían razón. Pero el collavino no cantaba, y los de la quebrada no podían bailar bien con ese canto. Tenía un ritmo lento y duro, como si molieran metal, y si el huayno era triste, parecía que el viento de las alturas, el aire que mueve a la paja y agita las pequeñas yerbas de la estepa, llegaba a la chichería. Entonces los viajeros recordábamos las nubes de altura, siempre llenas de amenaza, frías e inmisericordes, o la lluvia lóbrega y los campos de nieve interminables. Pero los collavinos eran festejados. Las mestizas, que no habían salido nunca de esas cuevas llenas de moscas, tugurios con olor a chicha y a guarapo ácido, se detenían para oírles.

Ellas sabían sólo huaynos del Apurímac y del Pachachaca, de la tierra tibia donde crecen la caña de azúcar y los árboles frutales. Cuando cantaban con sus voces delgaditas otro paisaje presentíamos; el ruido de las hojas grandes, el brillo de las cascadas que saltan entre arbustos 
y flores blancas de cactus, la lluvia pesada y tranquila que gotea sobre los campos de caña; las quebradas en que arden las flores del pisonay, llenas de hormigas rojas y de insectos voraces (pp. 45-46).

\section{Yllu - illa}

El zumbayllu-onomatopeya de trompo-se convertirá en un instrumento mágico, síntesis de movimiento-luz y movimiento-sonido, que de alguna manera participa a partir del sexto capítulo hasta el final de la novela.

Arguedas presenta al zumbayllu explicando las palabras quechuas illa e yllu.

La terminación quechua yllu es una onomatopeya. Yllu representa, en una de sus formas, la música que producen las pequeñas alas en vuelo; música que surge del movimiento de objetos leves. Esta voz tiene semejanza con otra más vasta illa. Illa nombra a cierta especie de luz y a los monstruos que nacieron heridos por los rayos de la luna. Illa es un niño de dos cabezas o un becerro que nace decapitado; o un peñasco gigante, todo negro y lúcido, cuya superficie apareciera cruzada por una vena ancha de roca blanca, de opaca luz; es también illa una mazorca cuyas hileras de maíz se entrecruzan o forman remolinos; son illas los toros míticos que habitan el fondo de los lagos solitarios, de las altas lagunas rodeadas de totora, pobladas de patos negros. Tocar un illa y morir o alcanzar la resurrección es posible. Esta voz ill 14 La cursiva es nuestra a tiene parentesco fonético y una cierta comunidad de sentido con la terminación yllu (p. 62).

Yllu, que es cierto tipo de sonido, puede entenderse fácilmente; sin embargo, illa es un término más complejo. En algunos relatos illa se dice que es un ser "reflejo" de otro ser, otras veces parecieran ser réplicas, de otros seres mayores. Las cualidades internas y, a veces, la apariencia externa que se observa ritualmente ${ }^{12}$ en una illa pertenece, de alguna manera, al ser del cual proviene y al cual alude ${ }^{13}$.

12 Entiendo como observación ritual, aquélla que se realiza cuando se observa un elemento u objeto, para saber del estado o situación de otro ser. Por ejemplo, se observa la coca, para leer el estado o situación de personas presentes o ausentes de la ceremonia ritual. De manera similar, se observa el fuego, elemento que ayuda a sentir o presentir.

13 La lógica de este procedimiento es similar al que se usa en la práctica de la medicina tradicional con el cuy. El animal es pasado por todo el cuerpo del 
El zumbayllu en funcionamiento contiene movimiento, luz-color y sonido, convirtiéndose en un illa, un ser que sintetiza, refleja o que es réplica de otro, ¿pero de cuál, de qué?

Para comprender las cualidades del zumbayllu, Arguedas incluye largos párrafos explicando las características de otros seres, especialmente los que causan asombro en el mundo andino, como el tankayllu (tábano zumbador), al que se le considera un ser especial.

Su color es raro, tabaco oscuro; en el vientre lleva unas rayas brillantes; y como el ruido de sus alas es intenso, demasiado fuerte para su pequeña figura, los indios creen que el tankayllu tiene en su cuerpo algo más que su sola vida. (...)

Pero los indios no consideran al tankayllu una criatura de Dios como todos los insectos comunes; temen que sea un réprobo. Alguna vez los misioneros debieron predicar contra él y otros seres privilegiados. En los pueblos de Ayacucho hubo un danzante de tijeras que ya se ha hecho legendario. Bailó en las plazas de los pueblos durante las grandes fiestas; hizo proezas infernales en las vísperas de los días santos; tragaba trozos de acero, se atravesaba el cuerpo con agujas y garfios; caminaba alrededor de los atrios con tres barretas entre los dientes; ese danzak' se llamó Tankayllu. Su traje era de piel de cóndor ornado de espejos (pp. 62-63).

En la cultura andina se encuentra muchas veces "la esencia" de un ser por su similitud cualitativa con otros. Diríamos que el danzaq estaba hecho "de lo mismo" que el tankayllu, como si el tankayllu fuera illa del danzaq y viceversa.

Más adelante el niño protagonista tratará de reconocer esa cualidad esencial de las personas que va conociendo; muchas veces, confundido se preguntará: “Qué, qué es, pues, la gente?" Y no será engañado por la vestimenta ni los ademanes de ciertas personas, como los oficiales del ejército, de quienes pensará que están disfrazados, que actúan como personajes que no son ellos mismos.

paciente, para diagnosticar una enfermedad. El diagnóstico se hace abriendo el cuerpo del animal y observando el estado de sus órganos. El estado de salud del paciente se verá reflejado en los órganos del animal y cualquier anomalía se cura en el cuerpo del mismo animal, mientras el paciente reposa. La práctica tiene semejanza con el vudú. La ciencia occidental no ha podido aún explicar hechos que se consideran parte de la magia de otras culturas; pero que la ciencia occidental no lo explique no quiere decir que no existan. 


\section{Pinkuyllu}

Para explicar el significado de yllu, Arguedas informa sobre el pinkuyllu y el waqrapuku, necesita detenerse en la descripción de las características morfológicas, los materiales y la técnica de construcción y de ejecución, el sentido social, el lugar, la ocasión y los efectos -la transformación interior- de los propios intérpretes y oyentes de la música hecha en dichos instrumentos.

Pinkuyllu es el nombre de la quena gigante que tocan los indios del sur durante las fiestas comunales. El pinkuyllu no se toca jamás en las fiestas de los hogares. Es un instrumento épico. No lo fabrican de caña común ni de carrizo, ni siquiera de mamak', caña selvática de grosor extraordinario y dos veces más larga que la caña brava. El hueco del mamak' es oscuro y profundo. En las regiones donde no existe el huaranhuay, los indios fabrican pinkuyllus menores de mamak' pero no se atreven a dar al instrumento el nombre de pinkuyllu, le llaman simplemente mamak' para diferenciarlo de la quena familiar. Mamak' quiere decir la madre, la germinadora, la que da origen; es un nombre mágico. Pero no hay caña natural que pueda servir de materia para un pinkuyllu; el hombre tiene que fabricarlo por sí mismo. Construye un mamak' más profundo y grave; como no nace ni aún en la selva. Una gran caña curva. Extrae el corazón de las ramas del huaranhuay, luego lo curva al sol y lo ajusta con nervios de toro. No es posible ver directamente la luz que entra por el hueco del extremo interior del madero vacío, sólo se distingue una penumbra que brota de la curva, un blando resplandor, como el del horizonte en que ha caído el sol.

El fabricante de pinkuyllus, abre los huecos de instrumento dejando aparentemente distancias excesivas entre uno y otro. Los dos primeros huecos deben ser cubiertos por el pulgar y el índice, o el anular, abriendo la mano izquierda en toda su extensión; los otros tres por el índice, el anular y el meñique de la mano derecha, con los dedos muy abiertos. Los indios de brazos cortos no pueden tocar pinkuyllu.

El instrumento es tan largo que el hombre mediano que pretende servirse de él tiene que estirar el cuello y levantar la cabeza como para mirar el cenit.

Lo tocan en tropas, acompañándose de tambores; en las plazas, el campo abierto o en los corrales y patios de las casas, no en el interior de las habitaciones.

Sólo la voz de los wak'rapukus es más grave y poderosa que la de los pinkuyllus. Pero en las regiones donde aparece el wak'rapuku ya no 
se conoce el pinkuyllu. Los dos sirven al hombre en trances semejantes. El wak'rapuku es una corneta hecha de cuernos de toro, de los cuernos más gruesos y torcidos. Le ponen boquilla de plata o de bronce. Su túnel sinuoso y húmedo es más impenetrable y oscuro que el del pinkuyllu, y como él, exige una selección entre los hombres que pueden tocarlo.

En el pinkuyllu y el wak'rapuku se tocan sólo canciones y danzas épicas. Los indios borrachos llegan a enfurecerse cantando las danzas guerreras antiguas; y mientras otros cantan y tocan, algunos se golpean ciegamente, se sangran y lloran después, junto a la sombra de las altas montañas, cerca de los abismos, o frente a los lagos fríos y la estepa.

Durante las fiestas religiosas no se oye el pinkuyllu ni el wak'rapuku. ¿Prohibían los misioneros que los indios tocaran en los templos, en los atrios o junto a los tronos de las procesiones católicas estos instrumentos de voz tan grave y extraña?

Tocan el pinkuyllu y el wak'rapuku en el acto de la renovación de las autoridades de la comunidad; en las feroces luchas de los jóvenes, durante los días de carnaval; para la hierra del ganado; en las corridas de toros. La voz del pinkuyllu o del wak'rapuku los ofusca, los exalta, desata sus fuerzas; desafían a la muerte mientras lo oyen. Van contra los toros salvajes, cantando y maldiciendo; abren caminos extensos o túneles en las rocas; danzan sin descanso, sin percibir el cambio de la luz ni del tiempo. El pinkuyllu y el wak'rapuku marcan el ritmo; los hurga y alimenta; ninguna onda, ninguna música, ningún elemento llega más hondo en el corazón humano.

La terminación yllu significa propagación de esta clase de música, e illa la propagación de la luz no solar. Killa es la luna e illapa el rayo. Illariy nombra al amanecer, la luz que brota por el filo del mundo, sin la presencia del sol. Illa no nombra la fija luz, la esplendente y sobrehumana luz solar. Denomina la luz menor: el claror, el relámpago, el rayo, toda luz vibrante. Estas especies de luz no totalmente divinas con las que el hombre peruano antiguo cree tener aún relaciones profundas, entre su sangre y la materia fulgurante (pp. 63-64).

\section{Zumbayllu}

En el internado, el trompo deja de ser juguete, para convertirse en un instrumento, con voz y luz especiales, un instrumento mágico. Las detalladas consideraciones dedicadas al pinkuyllu sirven de guía para apreciar la función del zumbayllu, actuando como instrumento mágico que dentro del internado se convertiría en el cristal en el que vibra el mundo. 
El descubrimiento del zumbayllu se hace a través del sonido. El protagonista se asombra al escuchar su canto.

Yo no pude ver al pequeño trompo ni la forma cómo Antero lo encordelaba (...).

Luego escuché un canto delgado.

Era aún temprano; las paredes del patio daban mucha sombra; el sol encendía la cal de los muros, por el lado del poniente. El aire de las quebradas profundas y el sol cálido no son propicios a la difusión de los sonidos; apagan el canto de las aves, lo absorben; en cambio, hay bosques que permiten estar siempre cerca de los pájaros que cantan. En los campos templados o fríos, la voz humana o la de las aves es llevada por el viento a grandes distancias. Sin embargo, bajo el sol denso, el canto del zumbayllu se propagó con una claridad extraña $a^{14}$; parecía tener agudo filo. Todo el aire debía estar henchido de esa voz delgada; y toda la tierra, ese piso arenoso del que parecía brotar.

¡Zumbayllu, zumbayllu!

Repetí muchas veces el nombre, mientras oía el zumbido del trompo. Era como un coro de grandes tankayllus fijos en un sitio, prisioneros sobre el polvo. Y causaba alegría repetir esta palabra, tan semejante al nombre de los dulces insectos que desaparecían cantando en la luz.

(...)

El canto del zumbayllu se internaba en el oído, avivaba en la memoria la imagen de los ríos, de los árboles negros que cuelgan en las paredes de los abismos.

(...)

Para mí era un ser nuevo, una aparición en el mundo hostil, un lazo que me unía a ese patio odiado, a ese valle doliente, al Colegio (pp. 65-66).

Al mismo tiempo, Ántero, el pelirrojo a quien llamaban Candela, lo descubre zumbayllero:

¡Como yo, zumbayllero de nacimiento! (p. 67).

\section{Layk'as}

Pero no sería el primer trompo que escuchara, el que se convertiría en objeto mágico, brujo, layk'a. Tenía que ser un winko, un ser especial,

14 La cursiva es nuestra. 
tan especial que sería deforme, porque tendría una forma que se sale de la norma; trabajado como el pinkuyllu, por una persona que le daría forma única al material. Su baile, su zumbido, sus colores, serían únicos también, y, para saber de su canto, se tendría que aguzar el oído, perfeccionar los sentidos tratando de comprender sus múltiples mensajes.

Como las voces del río, las aves, los árboles, que vibran en diversos paisajes externos, el canto del zumbayllu en el internado es el vínculo con un cosmos distinto al oficial, eclesiástico, del colegio. Para mantener su poder mágico, debía conservar la libertad primigenia, no ser bendito por ningún gesto ritual católico, debería permanecer maldito, con todo su poder.

Ernesto aprende a ser layk'a también. El primer mensaje, enviado en el canto del zumbayllu, fue para su padre.

Si lo hago bailar, y soplo su canto hacia la dirección de Chalhuanca, ¿llegaría hasta los oídos de mi padre? -pregunté al Mark'aska.

¡Llega, hermano! Para él no hay distancia. Enantes subió al sol. Es mentira que en el sol florezca el pisonay. ¡Creencias de indios! El sol es un astro candente, ¿no es cierto? ¿Qué flor puede haber? Pero el canto no se quema ni se hiela. ¡Un Layka winku con púa de naranjo, bien encordelado! Tú le hablas primero en uno de sus ojos, le das tu encargo, le orientas al camino, y después, cuando está cantando, soplas despacio hacia la dirección que quieres; y sigues dándole tu encargo. Y el zumbayllu canta al oído de quien te espera. ¡Haz la prueba, ahora, al instante!

- ¿Yo mismo tengo que hacerlo bailar? ¿Yo mismo?

- Sí. El que quiere el encargo.

- ¿Aquí en el empedrado?

- ¿Ya no lo viste? No lo engañes, no lo desanimes

Lo encordelé más cuidadosamente que otras veces. Y miré a Ántero.

- Háblale bajito -me advirtió.

Puse los labios sobre uno de sus ojos.

"Dile a mi padre que estoy resistiendo bien-dije- aunque mi corazón se asusta, estoy resistiendo. $Y$ le darás tu aire en la frente. Le cantarás para su alma".

Tiré la cuerda. 
¡Corriente arriba del Pachachaca, corriente arriba! Grité.

El zumbayllu cantó fuerte en el aire. Se paró en una de las gradas de madera que subían al corredor; saltó sobre las fibras de la madera vieja y se detuvo sobre una vena lúcida del piso.

- ¡Sopla! ¡Sopla un poco! Exclamó Antero.

Yo soplé hacia Chalhuanca, en dirección de la cuenca alta del gran río.

Cantó dulcemente (p. 107). 
